\title{
The interaction between personal and situational factors in developing future engineers' creativity
}

\author{
Aurel Mihail Țitu ${ }^{1, *}$, Claudiu Pirnau ${ }^{2}$, and Mironela Pirnau ${ }^{3}$ \\ ${ }^{1}$ Lucian Blaga University of Sibiu, 10 Victoriei Blvd, Sibiu, Romania \\ ${ }^{2}$ Politehnica University of Bucharest, 313 Splaiul Independentei, sector 6, Bucharest, Romania \\ ${ }^{3}$ Titu Maiorescu University, 187 Vacaresti Ave, sector 4, Bucharest, Romania
}

\begin{abstract}
The purpose of this paper is to analyze the interaction between the technological and the social field. Growth and development require a continuous source of ideas. Their manufacture is efficient only by stimulating the creativity development in the knowledge economy. This essential skill will lead to making smart products and technologies improvements. This will also be the result of the interactions between the new IT-cloud technologies and other various factors, such as: knowledge, skills, approaches, attention, motivation and intellectual property.
\end{abstract}

\section{Introduction}

In the context of higher education, the benefits of learning and personal development arise from defining the objectives of each student. The correlation of these objectives with the inner values and personal priorities leads to the creative and technical formation of future specialists. The target-setting trends arise from the interaction of the factors which contribute to the creativity and personality development. The factors influencing the future engineers' development fall into two categories: personal and situational. The main personal factors are represented by knowledge, skills and attitudes. Among the situational factors we mention attention, state of mind, motivation and reward [1].

A coherent and creative educational process, associated with innovative practical experience, results in maximizing the effect of the interactions between the two factors. Processing and implementing the knowledge gained by the engineering students are based on the interaction between personal and situational factors. According to the specialized literature [2], personal creativity, denoted by the letter "c" is specific to the individual, involving ideas or products new to a particular person. Creativity ' $\mathrm{C}$ ' implies the existence of new elements that receive social validation, being sufficiently valuable to be added to the culture. The interaction between the above mentioned factors is analyzed from two perspectives: technical higher education organizations and social media. In the four chapters hereof, this paper addresses interactions specific to the future engineers' professional development.

\footnotetext{
* Corresponding author: mihail.titu@ulbsibiu.ro
} 


\section{The interaction between cognitive science and engineering}

Cognitive sciences represent an interdisciplinary research field that integrates disciplines such as psychology, artificial intelligence, linguistics, philosophy, education, anthropology and neuroscience. The understanding level and the employment of the psychological knowledge specific for the people executing technical activities are very high. This fact is firstly generated by the volume and the complexity of the specific interactions, according to Table 1.

Table 1. Specific interactions related to the engineer profession.

\begin{tabular}{|c|l|}
\hline No. & \multicolumn{1}{c|}{ Type of interaction } \\
\hline 1. & Engineer - Engineer \\
\hline 2. & Engineer - Managers \\
\hline 3. & Engineer - Specialists in Economics and Finance \\
\hline 4. & Engineer - Subordinate staff \\
\hline 5. & Engineer - Systems (educational systems, cognitive systems etc.) \\
\hline 6. & Engineer - Collaborators \\
\hline 7. & Engineer - IoT (The Internet of things, also entitled The Industrial Internet) \\
\hline
\end{tabular}

The number of interactions is proportional to the size of the organization. The volume and the quality of the technical and psychological knowledge of a certain organization increase along with the number of employees and the used systems. Some of the latter are: calculation systems, operational systems, communication systems, data base systems, transport systems, production systems, cooling systems, construction site organization systems, ventilation systems etc. Regarding collaborators, they may be of a variety of professions such as doctors, when the engineers aim the medical institutions as beneficiaries. Within a type of economy based on knowledge, the knowledge engineer uses the knowledge data for two purposes: for the development of the artificial intelligence and for the regional intelligent development.

The new regional clusters contain within their hub four types of managers: the knowledge manager, the transverse manager, the facility manager and the senior sustainable development manager. The organization performance that learns is proportional to the performance of the intellectual capital. The engineers would be the first beneficiaries of the cognitive systems: the interactions between the artificial intelligence and Big Data (also known as Smart Inputs/Entries) would generate processes (called Smart Outputs) some of the self-learning (Machine Learning), all within a new science entitled Data Science. (For example: various universities offer Data Science master degree programs). The main domains that can be found at the intersection between the artificial intelligence and cognitive sciences are: psychology, linguistics and philosophy (Fig. 1). The interactions of many human experts and knowledge engineers lead to the effectiveness of the process of knowledge transfer and to the increase of the creativity level. Due to the fact that production systems are coordinated by specialists in technology, they will be analyzed in terms of features specific to engineers [3-4]. Example: A computational model for metaphors understanding is initially based on the representation of the meaning of the word "engineer".

The representation of the word can be localized (see Figure 2), corresponding to a single structure (concentrated in a single memory location) or distributed (see Figure 3), corresponding to a tree whose root is the meaning of the word and whose leaves are its individual features.

For these representations, the following main features of an engineer are used: analytical (centered on native curiosity), meticulous, communicative, creative (search for new, innovative ideas) logical, perfectionist, good mathematician, effective in finding crisis 
solutions, good team worker (integrates and works well in a team) and possessor of technical knowledge [5-6].

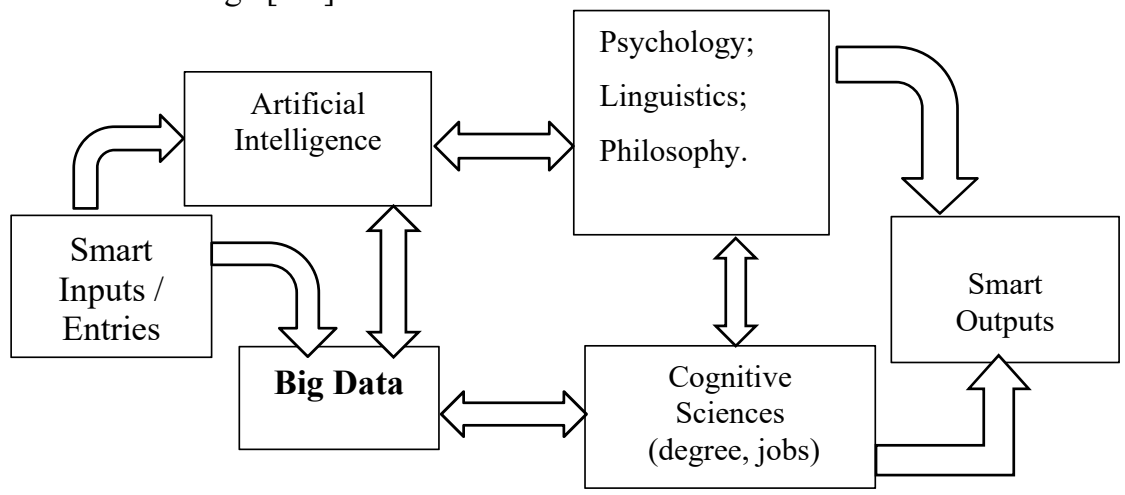

Fig. 1. Specific interactions of the cognitive systems.

The representation of a sentence such as "The engineer sketches products in the enterprise" can be achieved based on an edge-labeled tree as shown in Figure 4: the sentence is the root of the tree, the leaves are the words and the edges indicate the thematic role of each word. Each leaf represents a meaning of a word which may be represented in any of the forms shown in Figures 2 and 3. Thus, by applying cognitive sciences, models are performed and developed in order to represent the general knowledge of the subjects involved in the engineering field.

Engineer

Feature 1: analytic

Feature 2: meticulously

Feature 3: communicative

Feature 4: creatively

.

Fig. 2. Localized representation.

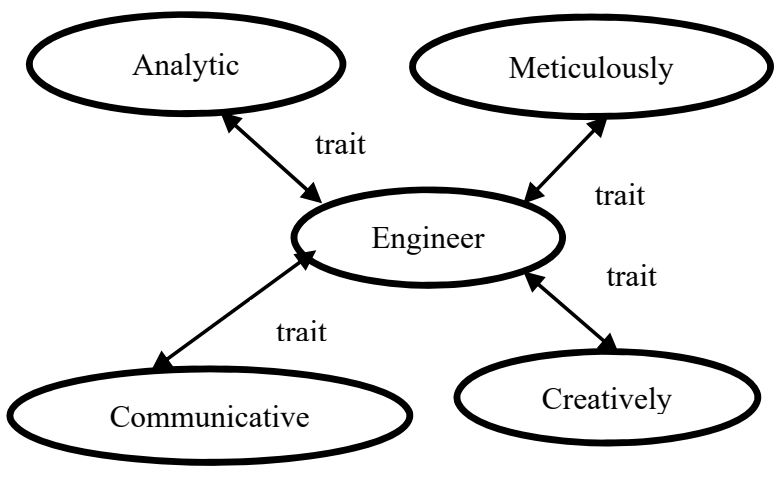

Fig. 3. Distributed representation.

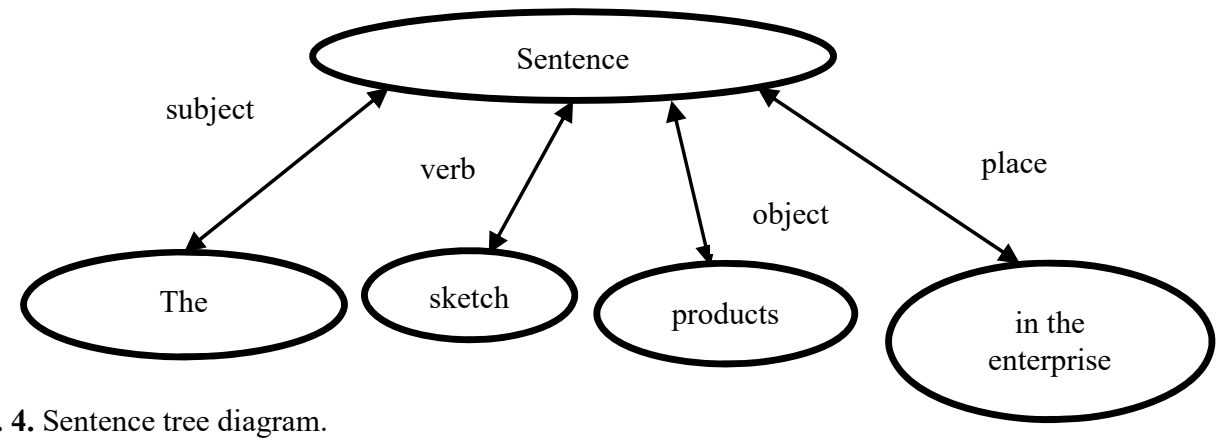

Since the majority of the models use interactions through the Internet services, nowadays it is even more important to emphasize the intellectual property role regarding the protection of the acquisition process and the knowledge transfer. 


\section{The role of intellectual property protection in engineering and related fields}

Ensuring that the policy on copyright, related rights and the protection of industrial property provides strong incentives for creativity, while promoting innovation in the knowledge-based economy is an important task of the actors involved in the technical higher educational process [7].

The copyright legislation is constantly adapting to technological changes (digital technology and networks), trying to find a balance between protecting the creative works and maintaining the advantages of the free flow of information.

The interaction between copyright and target audience (knowledge which contributes to the increase of the intellectual capital creativity) occurs through the instruments existing in the digital environment. The effectiveness and legality of these instruments may lead to the development of new business models, implicitly creating new jobs, so necessary in the context of forecasting the increase of the number of unemployed people (at least in Europe) due to the evolution of ITC [8].

Most interactions between intellectual property legislation and other factors that contribute to the sustainable development of the knowledge-based economy, take place on the Internet (cloud, social commerce, blogs etc.).

The objectives of the copyright policies at national level and policies on the use of Internet services worldwide can and should work in tandem. The sustainable Internet governance must rely on transparency, cooperation and strengthening the multilateral governance, which allows the development of creativity and innovation while simultaneously building trust and protecting certain important rights and interests [9].

Intellectual property laws (everything related to industrial property, copyright and related rights) interact mainly with: competition laws; norms regulating the consumption of medicines and drugs (implicitly their purchase by means of Internet services); legislation on foreign direct investment; standardization procedures (highly important in industrial and education activities in the engineering field); monopoly legislation (the interaction between intellectual property and competition); technology transfer; commercial law; consumer protection; human rights; innovation and diffusion of green / clean patents and technologies (design rights); human capital; biodiversity and knowledge (technical, traditional, economic etc.); Smart Sustainable Development (learning companies performance); international conventions in force etc. The status of engineering in the context of Intellectual Property Law is shown in Figure 5.

The intellectual property management is an important task for the teams of engineers. The usage of the social networks within various tasks represents an efficient method generated at the intersection between the digital economy and the one based on knowledge. [10-11].

\section{The interaction between social media and engineering}

The mass-media social engineering has different aims, depending on the enterprise and its domain, on the social network and its characteristics and on the interactions between the two entities, according to Table 2 [12].

Promoting the engineering field through social media must be included in the general marketing plan of the enterprise. In order to increase the impact two main elements are needed: creativity and authenticity. Whenever some beneficiaries are addressed, it is mandatory for the used social media channels to be analyzed. 


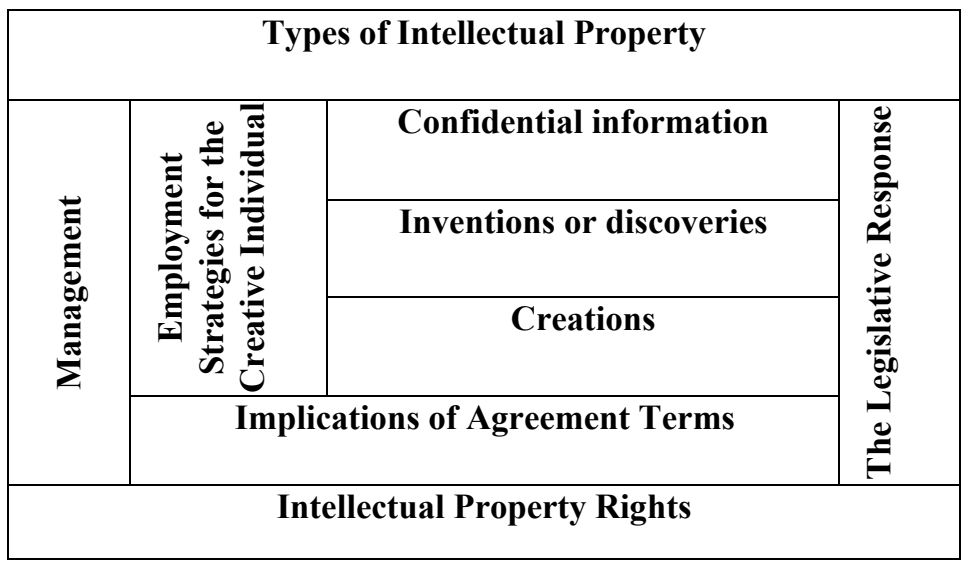

Fig. 5. Engineering in the context of Intellectual Property Law.

Table 2. Social Media Engineering Strategies.

\begin{tabular}{|l|l|l|}
\hline No. & $\begin{array}{l}\text { The name of the } \\
\text { social network }\end{array}$ & \multicolumn{1}{c|}{ Strategies / Type of article } \\
\hline 1. & LinkedIn & $\begin{array}{l}\text { How to create a profile that changes "heads"; The perfect resume; } \\
\text { The presentation of specific tendencies of certain industrial (the } \\
\text { division of a relevant content). }\end{array}$ \\
\hline 2. & Instagram & $\begin{array}{l}\text { Promoting the gender equality in specific engineering domains by } \\
\text { presenting female employees and their roles. }\end{array}$ \\
\hline 3. & Facebook & $\begin{array}{l}\text { Presenting the gender differences depending on the engineering } \\
\text { domain; The importance of the courses regarding the ongoing } \\
\text { professional training. }\end{array}$ \\
\hline 4. & Twitter & $\begin{array}{l}\text { The promoting campaigns of messages including logos and photos } \\
\text { (their main consequence is to increase the employees' loyalty); } \\
\text { Promoting certain events through strategies such as: "seize the day". } \\
\text { Example: photos from the hackathon, paintball or softball } \\
\text { championship; Promoting certain specific holidays. Example: } \\
\text { International Labor Day. }\end{array}$ \\
\hline
\end{tabular}

Thus, an accurate choice of the social media channel can be insured. The content of the messages must be addressed to the people themselves, and not to enterprises. Those who write and read messages are people who must be persuaded to repeat their involvement. In order to build a brand time is needed. This implies consistency at all levels: production, quality, marketing, management, social media etc. According to some studies performed by Cadenas Part Solutions LLC, $60 \%$ of the engineers use social media to find new products, and $53 \%$ of them use social media for product recommendations. A number of 8.522.177 of engineers are present on LinkedIn, and from those, a number of 3.054.315 are from SUA. The companies that accomplish design activities for CAD-CAM prefer social media such as Facebook, Twitter, LinkedIn, Google+ and Pinterest [13]. The instantaneous character of social media involves the fact that a potential client may contact the enterprise by asking questions regarding various posts, a procedure that cannot be performed in case of an email address or a phone number. Example: the Twitter lists allow the separation and the supervision of messages of distinct categories (clients, perspectives, competitors and professionals in engineering), thus these to be used whenever necessary.

The evaluation of the impact of social media engineering can be accomplished through certain coefficients and indicators. Their complex characteristic may be analyzed in a study of "Knowledge, creativity, innovation and promoting - KCIP" type. The KCIP acronym 
will become a symbol of specific interactions of the knowledge based economy: Social Media Engineering, IoT, Data Science, Intellectual Property, Artificial Intelligence etc.

\section{Conclusions}

The feedbacks generated from responses to specific questions will be constituted in new sets of knowledge and ideas. The interactions between cognitive science and engineering, as in the example shown, allow the creation and development of computational models. These models are based on artificial neural networks (self-learning intelligent systems) or production systems (designed and developed by means of the engineering specialists' creativity).

According to studies carried out herein, the intellectual property laws can be defined as a global interaction between organizational capital and the three dimensions of the intellectual capital: human, structural and relational. This interaction should be coordinated and driven in two directions: online and offline. The interactions map prioritizes online interactions based on the quantity and quality of existing and shared knowledge. The interactions in social media have highlighted the interdependence between knowledge discovery, knowledge engineering and knowledge management. The main reasons for the engineering companies to have a mass media activity are as follows: the need of marketing capacity growth, the diversification of the methods of communication to customers, the development of methods regarding targeting new clients and the possibility of creating new online professional community networks (Example: LinkedIn Mechanical Engineering Forum - 178.461 members).

Through new restructured concepts and knowledge, social media contributes to the development of loyalty of all types of employees, thus to the engineers. The use and growth of social media based on the interactions among knowledge, creativity, innovation and promotion also implies the promotion of creativity by validating creative thinking of students from the engineering domain.

\section{References}

1. R.M. Felder, North Carolina State University, CEE, 22(3), 120-125 (1988)

2. *** Encyclopedia of creativity, 1. A-H, AP, U.S.A. (1999)

3. F. Bouz, H. Dave, IBM Redbooks, NY, (2016)

4. L. Candy, Z. Bilda, ACM C\&C UC Berkeley CA, (2009)

5. T. Barrett, R. Donnelly, University College Dublin, DIT, In B. Higgs \& M. McCarthy (Eds.), EI II, (2008)

6. F.J. King, L. Goodson, F. Rohani, CALA, Florida State University, (1998)

7. M. Țîțu, C. Oprean, LAP Lambert Publishing House, ISBN-13 978-3-659-79332-5, ISBN-10 3659793329, Germany, (2015)

8. L. Bently, B. Sherman, 4th Edition, Oxford University Press, (2014)

9. ***The Department of Commerce. IPTF. USA, (2013)

10. K. Adams, National Center on Education and the Economy for the New Commission on the Skills of the American Workforce, (2006)

11. R. Miller, P. Heuzenroeder, S. Tso, A. Ruhrmann, Engineers Australia, Spruson \& Ferguson, (2013)

12. M.A. Storey, C. Treude, A. van Deursen, L.T. Cheng, Delft University of Technology, SERG, TRS, The Netherlands, (2010)

13. R. Zesch, Digital Parts Catalogs 101, SICM, 1-13, Cincinnati, USA, (2014) 